\title{
МОДЕРНИЗАЦИЯ ОРГАНИЗАЦИОННОЙ КУЛЬТУРЫ ПРЕДПРИЯТИЙ В ЭПОХУ ЦИФРОВЫХ ПРЕОБРАЗОВАНИЙ
}

Цель. Цель статьи состочт в выявлении ключевых барьеров, препятствующих эффективному развитию организационной культуры в условиях ияифровой экономики, $и$ разработке предложений по модернизаџии организаџионной культуры предприятий $c$ использованием информационно-коммуникационных технологий.

Методология / методика / подход. В статье использованы общенаучные методы абстракции и аналогии, индукичи и дедукциии, анализа и синтеза, обобщения, структурнологический, экономико-статистические, экспертных опросов, метод анализа иерархий.

Результаты. $B$ статье изложены результатьл проведенного эмпирического исследования для выявления современных проблем, барьеров, особенностей, тендениий и направлений модернизации организационной культуры украинских предприятий различных видов экономической деятельности. На основе метода анализа иерархий доказано, что оптимальным направлением модернизачии организационной культуры предприятий является внедрение иифровых технологий, поскольку он имеет самую большую эффрективность по сравнению с другими. Выявлены ключевые барьеры, сдерживающие эффективное развитие организачионной культурь предприятий в эпоху иифровых преобразований, которые условно классифицированы по семи группам: кадровые, информационные, организачионные, маркетинговые, образовательные, технологические, инвестиционно-финансовые.

Оригинальность / научная новизна. Впервые предложена содержательная структура организачионной культуры в цифрровой экономике, основными компонентами которой являются ичифровые навыки и компетентности, тип мышления и поведения, деловые взаимоотнотения и источники профессиональных знаний, модели развития карьеры. Обоснована челесообразность применения комплексного подхода к иифровой модернизации организационной культуры как симбиоза и постоянной взаимосвязи факторов влияния, составляюших элементов, цифровых компетенций и навыков, информационнокоммуникационных технологий.

Практическая ценность / значимость. Реализация предложений по модернизации организачионной культуры предприятий в эпоху цифровых преобразований способствует снижению вдвое затрат времени на трудоемкие процессы по управлению персоналом; повышению уровня вовлеченности сотрудников в процесс циифровизачии на 38\%; оптимизации управления компетенциями и навыками; ускорению запуска новых ичифровых решений на $33 \%$; повышению производительности сотрудников за счет применения клиентоориентированного подхода; снижению рисков при подборе персонала; повышению уровня логистического обслуживания; увеличению количества квалифицированных сотрудников; сокращению расходов на адаптацию, обучение и аттестацию персонала $u$ управления им в результате автоматизащии и оптимизащии HR-процессов до $90 \% u$ 


\title{
Agricultural and Resource Economics
}

\author{
www.are-journal.com
}

рационального инвестирования в развитие сотрудников; росту средней заработной плать сотрудников предприятий в результате оптимизачии административных расходов. Результаты исследования могут быть использованы публичными агропромымиленными компаниями.

Ключевые слова: организационная культура, барьеры, компоненты, модернизация, приоритетные направления, ијифровая экономика, информационно-коммуникационные технологии, эффект.

\section{Nataliia Trushkina ${ }^{1}$, Natalya Rynkevych ${ }^{2}$}

${ }^{1}$ Institute of Industrial Economics of National Academy of Sciences of Ukraine ${ }^{2}$ Prydniprovsk State Academy Construction and Architecture Ukraine

\section{MODERNIZATION OF ORGANIZATIONAL CULTURE OF ENTERPRISES IN THE EPOCH OF DIGITAL TRANSFORMATIONS}

Purpose. The purpose of the article is to identify key barriers to the effective development of organizational culture in the digital economy, and to develop proposals for the modernization of the organizational culture of enterprises using information and communication technologies.

Methodology / approach. The article uses general scientific methods of abstraction and analogy, induction and deduction, analysis and synthesis, generalization, structural-and-logical, economic-and-statistical, expert surveys, hierarchy analysis method.

Results. The article presents the results of empirical research to identify contemporary problems, barriers, features, trends and directions of modernization of the organizational culture of Ukrainian enterprises of various types of economic activity. On the basis of the hierarchy analysis method, it is proved that the introduction of digital technologies is the optimal direction for the modernization of the organizational culture of enterprises, since it has the greatest efficiency compared to others. The key barriers hindering the effective development of the organizational culture of enterprises in the era of digital transformations are identified, which are conditionally classified into seven groups: personnel, information, organizational, marketing, educational, technological, investment and financial.

Originality / scientific novelty. A substantial structure of organizational culture in the digital economy is proposed, for the first time, the main components of which are digital skills and competencies, the type of thinking and behavior, business relationships and sources of professional knowledge, career development models. The expediency of applying an integrated approach to digital modernization of organizational culture as a symbiosis and a constant relationship of influence factors, constituent elements, digital competencies and skills, information and communication technologies is substantiated.

Practical value / implications. The implementation of proposals for the modernization of the organizational culture of enterprises in the era of digital transformation contributes to halving the time-consuming processes of personnel management; increase in employee involvement in the digitalization process by $38 \%$; optimization of competency and skills management; accelerate the launch of new digital solutions by $33 \%$; increase employee productivity through a customeroriented approach; reduction of risks in the selection of personnel; improving the level of logistics services; increase the number of qualified employees; reducing the cost for adaptation, training and certification of personnel and their management as a result of automation and optimization of HR processes up to $90 \%$, and rational investment in employee development; growth in the average 


\section{Agricultural and Resource Economics}

www.are-journal.com

salary of company employees as a result of optimization of administrative costs. The results of the study can be used by public agro-industrial companies.

Key words: organizational culture, barriers, components, modernization, priority areas, digital economy, information and communication technologies, effect.

Постановка проблемы. Развитие современного информационного общества, цифровая трансформация бизнес-процессов с интенсивным применением цифровых технологий, повышение спроса на специалистов в сфере информационно-коммуникационных технологий, модернизация системы образования обуславливают коренные изменения в развитии организационной культуры и формируют качественно новые требования к уровню цифровых навыков и знаний персонала предприятий. Приоритетным заданием стратегических документов развития цифровой экономики и общества во многих странах мира является создание и реализация Национальных программ непрерывного обучения общим и профессиональным цифровым компетенциям и знаниям в контексте концепции обучения на протяжении всей жизни.

Вышесказанное четко иллюстрирует высокую потребность цифровых навыков на рынке труда и необходимость разработки и реализации комплекса мероприятий по трансформации организационной культуры предприятий в условиях стремительного развития цифровой экономики. Цифровая трансформация для каждого субъекта хозяйствования состоит в модернизации организационной культуры и внедрении цифровых технологий и коммуникаций, которые позволят расширить возможности и формировать собственную экосистему во взаимодействии со своими контактными аудиториями [1]. По оценкам McKinsey, повышение производительности труда за счет автоматизации бизнес-процессов на 45-55 \% является одной из важных перспектив отраслевого развития в эпоху глобальных цифровых преобразований [2].

Анализ и обобщение научной литературы подтверждают актуальность различных аспектов проблемы развития организационной культуры. Учеными уделяется значительное внимание становлению эволюционных взглядов к понятийному аппарату, исследованию современных тенденций, обоснованию научно-методических подходов и разработке предложений по совершенствованию управления развитием организационной культуры в системе менеджмента предприятий и в контексте корпоративной социальной ответственности. Вместе с тем многогранность, многоаспектность и дискуссионность отдельных вопросов по выбранной тематике обуславливает необходимость дальнейших научных исследований. И особенно решение этой проблемы актуализируется в современных условиях диджитализации экономических процессов.

Анализ последних исследований и публикаций. Изменение роли информационных технологий приобрело особую актуальность в контексте перехода к цифровой экономике, который активно обсуждается в последнее 


\section{Agricultural and Resource Economics}

www.are-journal.com

десятилетие в научной и предпринимательской среде. Информационные технологии влияют на формирование и развитие современных бизнес-моделей организаций. При этом роль ИТ в компаниях существенно изменилась. По мнению исследователей [3], информационные технологии уже не являются только инструментом организации и реализации бизнес-процессов; их превратили в «ресурс» с целью активизации инновационного развития предприятий и адекватного принятия технологических решений.

Компании заинтересованы в том, чтобы вклад информационных технологий в результаты их деятельности стал более измеримым, прямым и гибким [4]. Если раньше информационные технологии выполняли вспомогательные функции, то сегодня они выступают «движущей силой бизнес-инноваций» [5]. То есть, в настоящее время во многих странах мира «управление информационными технологиями трансформировалось из функции поддержки бизнеса в инструмент повышения эффективности и драйвера бизнес-инноваций и цифровой трансформации» [6, с. 53].

Следует отметить, что большинство ученых и практиков [7-12] проявляют сегодня значительный интерес к решению проблем цифровизации бизнеспроцессов. Однако до сих пор не существует единого подхода к определению понятия «цифровизация». Это обусловлено тем, ученые представляют разные научные школы, которым присуща своя специфика. По мнению В. Ниссена, Т. Лезиной, А. Салтана, «...Цифровизацию можно определить как целенаправленные усилия компаний по активному использованию цифровых технологий на всех уровнях для оптимизации внутренних процессов и модификации общей модели ведения бизнеса» [8, с. 55].

С позиции компаний цифровизация затрагивает все структурные аспекты бизнеса, включая цели, бизнес-модели, бизнес-процессы. Ключевая задача цифровизации состоит в оптимальном использовании информационных ресурсов, технологий и систем с целью повышения уровня производительности персонала и сокращения затрат на организацию бизнес-процессов.

То есть, цифровая трансформация является вызовом времени и может рассматриваться как радикальные изменения комплекса бизнес-процессов, начиная от разработки продукции и заканчивая обслуживанием потребителей, а также внедрение современных цифровых технологий при организации бизнеспроцессов на предприятиях. При этом «важным фактором, определяющим успех создания новой стоимости через инвестиции в информационные технологии, служит интеграция бизнеса и ИТ как взаимное соответствие и взаимодополнение бизнес- и ИТ-структур» [9].

Добиться этой интеграции возможно только при использовании инструментов ИТ-менеджмента, «который рассматривается как специально разработанный комплекс механизмов управления ИТ, обеспечивающий поддержку целей, стратегии, системы ценностей, норм и культуры компании» [13]. К основным задачам ИТ-менеджмента можно отнести непрерывное предоставление качественных информационных услуг и совершенствование 


\section{Agricultural and Resource Economics}

www.are-journal.com

организации бизнес-процессов [14].

Для повышения уровня прибыльности компании должны разработать четкие цифровые стратегии, определять цифровые приоритеты, трансформировать организационную культуру с применением информационнокоммуникационных технологий и совершенствовать систему управления персоналом [15]. В настоящее время в научной литературе появилась экономическая категория «информационная прибыльность», которая означает способность компании оптимально и систематически использовать информацию для достижения стратегических целей - это способ объединения информационных навыков компании с теми преимуществами, которые дают электронные формы обмена» [16].

Японский экономист Й. Нонака обосновал целесообразность формирования «компании, создающей знание», то есть такой компании, которая может быстро продуцировать новые и соответствующие современной экономической жизни методы контроля и управления, внедрять передовые технологии, что обеспечивает тесные коммуникационные связи между различными подразделениями компании и общую когнитивную основу для взаимодействия сотрудников компании» [17].

Знание становится ресурсом, а экономическая деятельность, основанная на ограниченности ресурсов, уступает место экономической деятельности, основанной на информации и способах ее передачи [15]. В цифровой среде меняется организационная культура, в частности - этика компании. Американские экономисты Р. Каплан и Д. Нортон выдвинули несколько допущений, на базе которых необходимо осуществлять деятельность и управление фирмой в информационном обществе. Среди них основополагающая роль высококвалифицированных кадров [18].

Анализ показывает, что в научных публикациях [19-40] ученые уделяют существенное внимание выявлению факторов влияния организационной культуры на эффективность и уровень конкурентоспособности предприятий; научно-методическому обоснованию взаимосвязи между организационной культурой и финансовыми результатами; разработке методик оценки уровня развития организационной культуры; применению информационных технологий в деятельности предприятий, в тому числе для совершенствования системы управления персоналом.

С внедрением цифровых технологий организационная культура предприятий в последнее время претерпевает значительных трансформационных изменений, которые способствуют формированию и развитию цифровой культуры (рис. 1).

При этом эксперты прогнозируют, что к 2030 г. 57 профессий будут не востребованы на рынке труда в разных сферах экономической деятельности. Но взамен ушедшим профессиям возникнут новые 186 профессий, которые будут требовать качественно нового уровня знаний, то есть цифрового. Европейская комиссия выделяет пять измерений программы развития цифрового 


\section{Agricultural and Resource Economics \\ www.are-journal.com}

предпринимательства: цифровые знания и рынок информационнокоммуникационных технологий; цифровая бизнес-среда; доступ к финансам для бизнеса; цифровые навыки работающих и электронное лидерство; создание поддерживающей предпринимательской культуры [42].

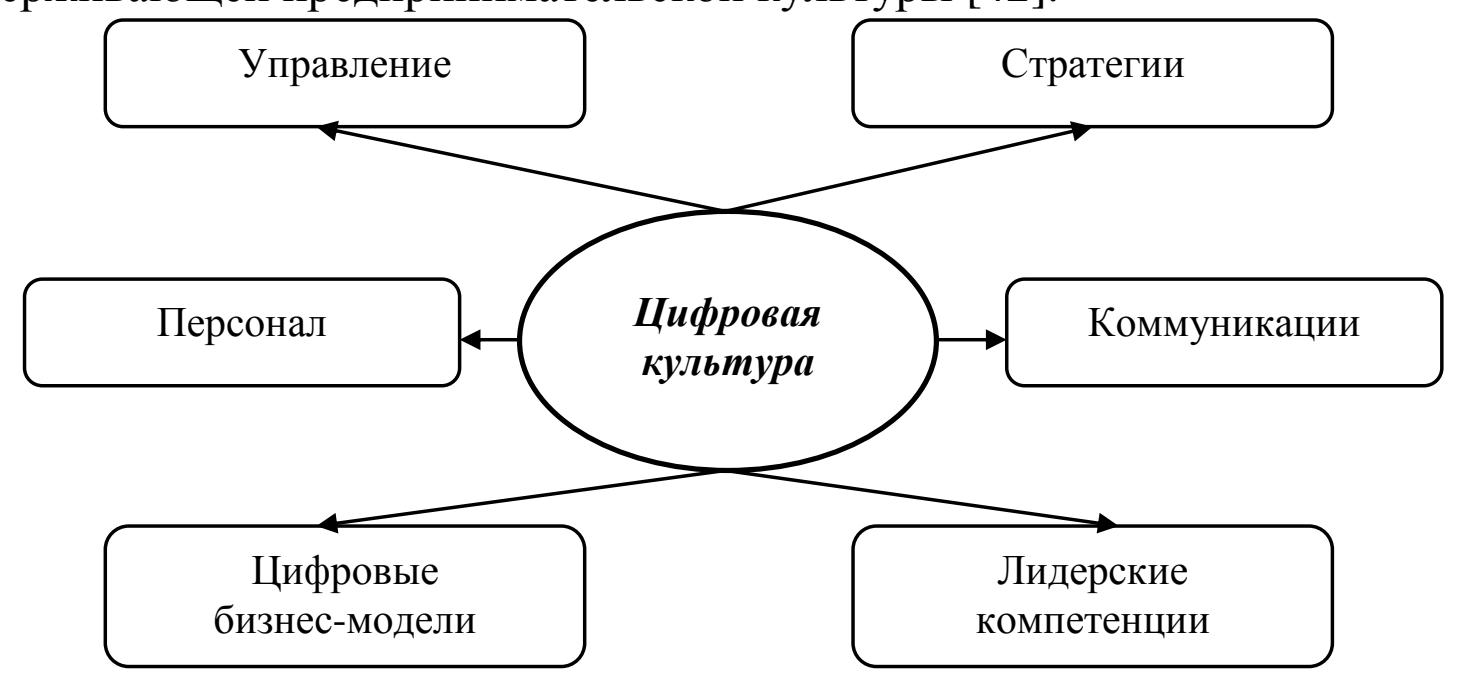

Рис. 1. Элементы организационных трансформаций в условиях цифровой экономики

Источник: адаптировано и построено на основе [41].

Авторы эмпирического исследования Digital Business Redefines Talent Management Applications, проведенного консалтинговой компанией Gartner, пришли к выводу, что к 2022 г. 80 \% организационных навыков в компаниях должны быть пересмотрены из-за цифровой трансформации [43].

Таким образом, необходимость в постоянном обучении с целью приобретения новых навыков, поощрение этого процесса и создание благоприятных условий для развития персонала становится неотъемлемой частью организационной культуры любого современного предприятия (в том числе агропромышленных компаний) в условиях цифровой экономики.

Цель статьи. Цель статьи состоит в выявлении ключевых барьеров, препятствующих эффективному развитию организационной культуры в условиях цифровой экономики, и разработке предложений по модернизации организационной культуры предприятий с использованием информационнокоммуникационных технологий.

Изложение основного материала исследования. К ключевым направлениям цифровой трансформации относится изменение организационной культуры, преобразование бизнес-моделей и продукции, обеспечение роста гибкости предприятий. В ежегодном исследовании State of Digital Transformation компании Altimeter отмечается, что на современном этапе возрастает роль и значение организационной культуры, которая создает возможности для модернизации, роста инноваций и их ускорения. Около $95 \%$ руководителей компаний говорят о необходимости трансформации корпоративной культуры [44].

По экспертным оценкам компании Cisco, цифровизация влияет на 


\section{Agricultural and Resource Economics \\ www.are-journal.com}

организацию бизнес-процессов в десять раз больше, чем Интернет [45]. Согласно расчетам специалистов компании International Data Corporation, экономический эффект от цифровой трансформации может достигать 20 трлн долл. США, то есть около $20 \%$ ВВП [46]. В результате обследования более 400 крупных компаний разных сфер экономической деятельности, проведенного компаниями Capgemini Consulting и MIT Sloan Management, установлено, что уровень рентабельности предприятий, использующих в работе цифровые технологии и инновационные методы менеджмента и маркетинга, на $26 \%$ выше по сравнению с конкурентами. Темпы роста прибыли компаний, которые нацелены только лишь на улучшение менеджмента, составляют $9 \%$. При этом на $11 \%$ ниже уровень прибыльности компаний, которые вкладывают существенные инвестиции в цифровые технологии, но не занимаются решением проблем менеджмента. А предприятия, которые не уделяют внимание совершенствованию системы управления, и внедрению информационных технологий, недополучают прибыли около 24 \% [47].

В ходе исследования компании BCG установлено, что около $80 \%$ предприятий, сфокусированных на организационной культуре, стабильно показывают высокие результаты производительности. На основе оценки 40 цифровых трансформаций обнаружено, что удельный вес компаний, сообщающих о прорыве или сильных финансовых показателях, в пять раз выше (90 \%) среди тех, кто ориентировался на оргкультуру, чем среди тех, кто ею пренебрегал (17 \%) [48]. Диагностика организационной культуры 75 публичных компаний показывает четкую взаимосвязь между силой оргкультуры предприятий и их финансовыми показателями. Доказано, что TSR (общий доход акционеров) компаний с сильной организационной культурой $(24 \%)$ за пять лет был в два раза больше, чем у компаний со средней культурой (13\%) и в 2,4 раза превышал TSR компаний со слабой оргкультурой (10\%). Эффект в производительности также очевиден в долгосрочной перспективе: у компаний с сильной организационной культурой десятилетний TSR примерно в два раза больше, чем у компаний со смешанной культурой [48].

В настоящее время разработано большое количество методик оценки цифровой трансформации бизнес-процессов предприятий, одной из составляющих которых является организационная культура (табл. 1).

Методики оценки трансформации бизнес-процессов предприятий

\begin{tabular}{|l|l|}
\hline \multicolumn{1}{|c|}{ Название } & \multicolumn{1}{|c|}{ Содержание } \\
\hline \multicolumn{1}{|c|}{1} & \multicolumn{1}{|c|}{2} \\
\hline $\begin{array}{l}\text { Модель цифровой } \\
\text { зрелости компании } \\
\text { Deloitte }\end{array}$ & $\begin{array}{l}\text { Оценка цифровых возможностей по 5 ключевым измерениям: } \\
\text { потребители; стратегия; технологии; производство; структура и } \\
\text { культура }\end{array}$ \\
\hline $\begin{array}{l}\text { Индекс цифровой } \\
\text { трансформации } \\
\text { (аналитическое агентство } \\
\text { Arthur D. Little) }\end{array}$ & $\begin{array}{l}\text { Направления оценки: стратегия и руководство; продукты и } \\
\text { кервисы; управление клиентами; операции и цепочки поставок; } \\
\text { технологии; рабочее место и культура }\end{array}$ \\
\hline
\end{tabular}




\begin{tabular}{|c|c|}
\hline & л. \\
\hline 1 & 2 \\
\hline $\begin{array}{l}\text { Индекс цифровой } \\
\text { зрелости предприятий }\end{array}$ & $\begin{array}{l}5 \text { укрупненных направлений оценки: стратегия и бизнес- } \\
\text { модель; потребители; организационная культура и персонал; } \\
\text { операционные процессы; информационные технологии }\end{array}$ \\
\hline $\begin{array}{l}\text { Модель оценки цифровых } \\
\text { способностей компании } \\
\text { KPMG }\end{array}$ & $\begin{array}{l}5 \text { направлений оценки: видение и стратегия; цифровые } \\
\text { таланты; ключевые цифровые процессы; гибкие источники и } \\
\text { технологии; руководство }\end{array}$ \\
\hline $\begin{array}{l}\text { Модель «Цифровое } \\
\text { пианино», разработанная } \\
\text { Global Center for Digital } \\
\text { Business Transformation по } \\
\text { инициативе компаний } \\
\text { IMD и Cisco }\end{array}$ & $\begin{array}{l}7 \text { трансформационных категорий, составляющих наиболее } \\
\text { важные элементы цепочки создания стоимости организации: } \\
\text { бизнес-модель; организационная структура; сотрудники; } \\
\text { процессы; ИТ-возможности; } \\
\text { взаимодействия }\end{array}$ \\
\hline $\begin{array}{l}\text { Индекс изменений } \\
\text { цифрового } \\
\text { преобразования, } \\
\text { предложенный компанией } \\
\text { Ionology }\end{array}$ & $\begin{array}{l}5 \text { блоков: стратегия и культура; персонал и клиенты; процессы } \\
\text { и инновации; технологии; данные и аналитика }\end{array}$ \\
\hline $\begin{array}{l}\text { Индекс зрелости } \\
\text { Индустрии } 4.0 \text { Acatech, } \\
\text { разработанный } \\
\text { Национальной академией } \\
\text { наук и техники Германии } \\
\end{array}$ & $\begin{array}{l}4 \text { ключевые области цифровой трансформации: ресурсы; } \\
\text { информационные системы; культура; } \\
\text { структура. Организационная } \\
\text { организационной структуры и культуры }\end{array}$ \\
\hline $\begin{array}{l}\text { Индекс стратегических } \\
\text { преобразований в } \\
\text { процессе цифровой } \\
\text { трансформации, } \\
\text { предложенный } \\
\text { российской компанией } \\
\text { Команда-А (КМДА) }\end{array}$ & $\begin{array}{l}6 \text { основных направлений: клиентоиентричность (цифровой } \\
\text { клиентский сервис, омниканальность, цифровой маркетинг и } \\
\text { коммуникации); коллаборация (представление бизнеса как } \\
\text { экосистемы, создание и развитие платформы для } \\
\text { взаимодействия с партнерами); данныле (широкое применение } \\
\text { аналитических инструментов, использование данных для } \\
\text { адаптации продуктов и сервисов, поведенческий маркетинг); } \\
\text { инновации (инновационная культура внутри компании, } \\
\text { построение системы непрерывных улучшений и развития); } \\
\text { ценность (определение и построение системы управления } \\
\text { ценностными предложениями); персонал (новые подходы к } \\
\text { вовлечению и развитию сотрудников на основе цифровой } \\
\text { культуры и мышления) }\end{array}$ \\
\hline едприяา & $\begin{array}{l}\text { Направления, по которым может оценить уровень цифровой } \\
\text { зрелости: уточнение, формирование единой стратегии } \\
\text { цифровой трансформации; анализ и оценка эффективности } \\
\text { применяемых программных сервисов и платформ; оценка } \\
\text { уровня цифрового маркетинга и коммуникаций; участие в } \\
\text { процессе разработки программных продуктов; внедрение Agile } \\
\text { IT; анализ, оценка, аудит цифровых процессов; уровень } \\
\text { организационной культуры; уровень инновационного } \\
\text { потенциала предприятия; оценка оборудования и систем и их } \\
\text { последующая модернизация; изучение конкурентной среды }\end{array}$ \\
\hline
\end{tabular}

Источник: обобщено и составлено авторами на основе [49; 50].

Однако, обобщение аналитических отчетов международных организаций 


\section{Agricultural and Resource Economics \\ www.are-journal.com}

свидетельствует о том, что одним из наиболее существенных препятствий успешных цифровых преобразований является отсутствие необходимой организационной культуры и неготовность персонала (включая менеджеров различных уровней управления) к работе в новых условиях. Так, исследования CGI Global 1000, проведенного в 2016 г. компанией CGI Group [51], показали, что ключевым барьером для цифровой трансформации является изменение организационной культуры и преодоление сопротивления со стороны сотрудников компании. Эту причину назвали 72 \% опрошенных.

Экспертное анкетирование 116 руководителей из 18 стран мира, проведенное в 2017 г. специалистами Технического университета в Мюнхене (TUM) совместно с SAP и IDT [52], позволило установить, что для эффективного внедрения цифровых технологий для бизнес-инноваций недостаточно только технологических навыков. $84 \%$ респондентов считают, что навыки управления изменениями в бизнесе важны для цифровой трансформации. При этом только 15 \% специалистов полагают, что обладают навыками, необходимыми для реализации цифровых процессов, в то время как 64 \% считают, что вовсе не владеют подобными компетенциями (табл. 2).

Таблицуа 2

Навыки, доступные и необходимые для цифровой трансформации с целью повышения эффективности бизнес-процессов

\begin{tabular}{|l|c|c|}
\hline \multirow{2}{*}{\multicolumn{1}{|c|}{ Перечень навыков }} & \multicolumn{2}{|c|}{ Удельный вес навыков, \% } \\
\cline { 2 - 3 } & $\begin{array}{c}\text { доступных в компаниях для } \\
\text { цифровой трансформации }\end{array}$ & $\begin{array}{c}\text { необходимых для цифровой } \\
\text { трансформации }\end{array}$ \\
\hline Социальные медиа & 57 & 63 \\
\hline Облачные вычисления & 49 & 76 \\
\hline Мобильные технологии & 46 & 87 \\
\hline $\begin{array}{l}\text { Управление изменениями в } \\
\text { бизнесе }\end{array}$ & 46 & 84 \\
\hline Цифровая безопасность & 45 & 88 \\
\hline Базы данных и памяти & 43 & 65 \\
\hline Бизнес-сети & 42 & 71 \\
\hline Интеграция продукт / сервис & 36 & 66 \\
\hline Аналитика Віg Dата & 34 & 84 \\
\hline Предпринимательство & 34 & 65 \\
\hline Интернет вещей & 32 & 75 \\
\hline Новые интерфейсы & 29 & 50 \\
\hline Блокчейн & 24 & 36 \\
\hline Искусственный интеллект & 21 & 56 \\
\hline
\end{tabular}

Источник: составлено авторами на основе [52].

Устранение разрыва между необходимыми цифровыми навыками и имеющимися у персонала компаний, по мнению опрошенных, будет основным средством успешных преобразований. Тем не менее только $16 \%$ респондентов подготовили и реализуют специальную программу найма или обучения для создания базы навыков, необходимых для формирования цифрового будущего компаний. Как утверждают эксперты, инвестирование в образование и 


\section{Agricultural and Resource Economics}

www.are-journal.com

обучение сотрудников приобретает большое значение, поскольку развитие цифровых знаний у персонала является предпосылкой для непрерывной цифровой трансформации бизнес-процессов предприятий [52].

О необходимости цифровой трансформации, согласно обследованию компании СІО в 2018 г., заявляют 39 \% организаций, но лишь 35 \% обладают навыками, требуемыми для ее успешного проведения. Руководителям предприятий не удается направить сотрудников на путь цифровизации. Они не могут сформировать для этого организационную культуру, что негативно отражается на уровне вовлеченности персонала. В 2018 г. только $36 \%$ организаций отмечают, что у каждого есть возможность принять участие в обсуждении цифровых инициатив. У сотрудников нет стремления добиваться целей цифровой трансформации и прилагать усилия к личному развитию. Большинство компаний неспособны правильно управлять изменениями. О наличии четко определенных цифровых инициатив заявили $32 \%$. Только $40 \%$ опрошенных сообщили о существовании процессов, гарантирующих соответствие усилий в сфере цифровых преобразований корпоративным целям. Установлено, что незначительная часть ИТ-директоров уделяют должное внимание передовым технологиям. Например, в Интернет вещей инвестируют всего $29 \%$ респондентов; искусственный интеллект - $17 \%$; блокчейн $-11 \%$; в дополненную реальность - $10 \%$ [53].

Компания Russel Reynolds Associates опросила более 2000 топ-менеджеров из 15 отраслей о влиянии цифровых технологий на их бизнес. $90 \%$ компаний уже разработали цифровую стратегию развития, однако во многих организациях недостаток квалифицированных кадров препятствует еe реализации. Лишь 50 \% респондентов ответили утвердительно на вопрос «Есть ли у Вас нужные люди для работы над цифровой стратегией компании?» [54].

В ходе опроса 700 представителей более 300 российских компаний из 15 отраслей, проведенного компанией КМДА в 2018 г., обнаружены главные барьеры цифровой трансформации предприятий, среди которых: недостаточные компетенции и знания $(64,1 \%$ респондентов); нехватка квалифицированных кадров (60,9\%); отсутствие стратегии $(53,2 \%)$; страх изменений $(45,3 \%) ;$ недостаточное финансирование $(39,1 \%) ;$ позиция руководства $(31,3 \%) ;$ риски $(23,4 \%)[50 ; 55]$.

$70,3 \%$ опрошенных ответили, что для улучшения ситуации с дефицитом компетенций занимаются поиском новых специалистов. Значительная часть $(65,6 \%)$ респондентов также отметили, что стремятся повышать квалификацию ныне работающих сотрудников («старых»), так как уверены в их трудоспособности и лояльности к компании. 15,6 \% экспертов посчитали, что им не нужно предпринимать какие-то шаги в этом направлении, поскольку в их компании и так достаточно компетентных сотрудников. Большая часть опрошенных $(21,9 \%)$ оценила квалификацию своего персонала на 6 из 10 баллов; 4,7 \% - на 10 из 10. Но основная часть оценок (49,9\%) оказалась в диапазоне от 1 до 5 , что еще раз доказывает о существующих проблемах в 


\section{Agricultural and Resource Economics}

www.are-journal.com

развитии цифровых компетенций у сотрудников. Наиболее важными цифровыми компетенциями сотрудников названы: гибкость и обучаемость (61\% респондентов); аналитические компетенции (55\%); знание инновационных технологий (53\%); понимание методов и процессов (51\%); широкий кругозор и креативность $(47 \%)$; понимание сути цифровой трансформации (42\%); умение использовать большие данные (34\%); навыки программирования (21\%) [55].

Исследование, проведенное компанией Oliver Wyman в январе-марте 2019 г., подтвердило, с одной стороны, повышение значения корпоративной культуры как инструмента реализации организационной стратегии в условиях цифровой эпохи, а с другой стороны, отсутствие должного внимания руководства к вопросам корпоративной культуры. В результате опроса были получены экспертные оценки на следующие вопросы [56]:

«Насколько важна роль корпоративной культуры в достижении стратегических задач?» - 7,4 балла;

«Насколько старшее руководство понимает важность роли, которую играет корпоративная культура?»-6,1 балл;

«Насколько эффективно выстроен процесс коммуникации в компании в целом?»-3,8 балла;

«Насколько эффективно корпоративная культура помогает в реализации изменений или трансформации?» - 6,7 балла.

В феврале 2019 г. компания Coleman Services провела эмпирическое исследование «Функции HR: актуальные задачи, приоритеты, вызовы» методом онлайн-опроса HR-специалистов 69 предприятий в сферах промышленности и услуг. В результате опроса определены ключевые направления цифровизации HR-функций в компаниях, среди них: кадровое администрирование (77\% респондентов); оценка персонала (55\%); обучение и развитие персонала (32\%); внутренние коммуникации (23\%); функция подбора персонала (21\%) [57].

На сегодняшний день в большинстве международных компаний отсутствует цифровая культура. Во-первых, это обусловлено неправильным пониманием сущности термина «цифровая трансформация». Во-вторых, основная масса сотрудников пока не обладает мотивацией и необходимыми цифровыми навыками и компетенциями, чтобы участвовать в качественных изменениях организационной культуры [50].

Это подтверждают и полученные результаты анкетирования «Проблема цифровой культуры: ликвидация пробела между сотрудниками и руководителями», в котором приняло участие 340 европейских и американских компаний из 5 отраслей. $40 \%$ руководителей считают, что в их компаниях уже существует цифровая культура, но с ними согласны всего 27 подчиненных [58].

В ходе маркетингового исследования, проведенного аналитическим центром НАФИ и Сколково, установлено, что уровень владения цифровыми навыками сотрудниками российских компаний ниже среднего; предприятия в целом уделяют сравнительно низкое внимание обучению сотрудников в сфере 


\section{Agricultural and Resource Economics \\ www.are-journal.com}

цифровых технологий; высокотехнологичные стартапы показывают более высокий уровень активности: образовательные программы в сфере цифровых технологий реализованы у 33\% респондентов. Недостаточно низкий уровень цифровизации связан и с тем, что предприятия акцентируют внимание на технологической модернизации и внедрении информационнокоммуникационных технологиях и недооценивают организационные аспекты, к которым относится цифровая культура, лидерские компетенции и кадры [41].

Таким образом, потребность в высококвалифицированной рабочей силе резко возрастает - и особенно в специалистах по цифровым технологиям, аналитике данных и сотрудниках, получивших образование в сфере науки, технологий, инжиниринга и математики (STEM), - новые методы поиска персонала и программы подготовки, сформированные с учетом задач Индустрии 4.0, будут иметь решающее значение в долгосрочной перспективе.

Персонал является центральным элементом цифровой трансформации. Вместе с тем, Глобальное исследование цифровых операций в 2018 г. «Цифровые чемпионы. Как лидеры создают интегрированные операционные экосистемы для разработки комплексных решений для потребителей» показало, что 2/3 всех компаний не имеют четкого цифрового видения и стратегии для поддержания процесса цифровой трансформации и соответствующей корпоративной культуры. Лишь $27 \%$ респондентов заявили о том, что их сотрудники обладают необходимой квалификацией, чтобы воплотить цифровое будущее в деятельности компании. Опрос 1155 международных компаний позволил определить, каким образом корпоративная культура и организационная структура способствует цифровой трансформации:

- неудачи считаются признанной частью процесса развития (38\% респондентов);

- компания имеет горизонтальные иерархии, которые позволяют достичь гибкости в работе и ускорить процесс принятия решений (37 \%);

- ориентация на обеспечение цифрового качества обслуживания на протяжении всего процесса работы с клиентами (35\%);

- руководство компании имеет четкое представление о цифровом будущем и выступает в качестве ролевой модели (34 \%);

- компания поощряет культуру инноваций за счет привлечения мультидисциплинарных групп (32\%);

- компания выборочно привлекает экспертных партнеров в качестве дополнительных внешних ресурсов (32\%);

- сотрудники обладают необходимой квалификацией для цифрового будущего (27\%);

- компания вкладывает значительный объем инвестиций в обучение, чтобы подготовить сотрудников к цифровой трансформации (26\%);

- в компании создаются учебные группы, объединяющие цифровое поколение и опытных сотрудников (22 \%) [59].

Специалисты MIT Sloan Management Review и Deloitte University Press 


\section{Agricultural and Resource Economics}

www.are-journal.com

выяснили, что более $75 \%$ опрошенных предоставляют своим сотрудникам ресурсы и возможности для развития цифровых навыков и компетенций. 71\% компаний с высоким уровнем цифровой зрелости утверждают, что они привлекают новые таланты на основе использования цифровых технологий и инвестируют их, в то время как только 10 \% из них могут это делать на ранней стадии [60].

В июне-августе 2019 г. было проведено собственное эмпирическое исследование особенностей развития организационной культуры предприятий разных видов экономической деятельности в Украине [61-64]. Было опрошено 115 экспертов в сфере пищевой промышленности, угольной отрасли, строительства, оптовой и розничной торговли, услуг (транспортные, банковские, консалтинговые, интернет-услуги, энергетические, бытовые услуги населению), образования и науки, государственного управления.

Установлено, что организационной культуре обследованных предприятий присущи следующие особенности и отличия [61]:

- на формирование оргкультуры большее влияние оказывают топменеджеры (63,5 \% опрошенных); меньше влияют менеджеры среднего звена $(11,3 \%)$, HR-отдел $(11,3 \%)$, рядовые сотрудники $(10,4 \%)$ и клиенты $(10,4 \%)$;

- организационная культура, как правило, сформирована руководством $(78,3 \%)$, остальные эксперты $(13 \%)$ отметили, что она сформирована спонтанно, а 8,7\% опрошенных утверждают, что у них и вовсе нет организационной культуры;

- организационная культура компании является неэффективной (36,5 \% респондентов) и имеет ряд недостатков: препятствие функциональной разобщенности обмену данными (18,3\%); организация сфокусирована на продажах и прибылях, а не на потребителе, то есть компания не сориентирована на клиента (14,8 \%); непонимание сотрудников предприятия, что такое «клиентоориентированный подход к формированию организационной культуры» $(12,2 \%) ; \quad$ отсутствие общепринятого определения клиентоориентированности $(11,3 \%)$; организационная культура не выстроена вокруг потребностей клиентов (11,3\%); отсутствие цифровых платформ, позволяющих управлять данными $(10,4 \%)$; недостаточная цифровая компетентность персонала компании (8,7\%); неспособность в компании поддерживать маркетинговые коммуникации с клиентами (5,2%);

- ключевые преграды по изменению организационной культуры компаний в условиях цифровой экономики: низкий уровень вовлеченности сотрудников (28,7 \% респондентов); недостаточный объем финансовых ресурсов (27,8 \%); несовершенство организационной структуры $(27,0 \%)$; отсутствие четкого видения и поддержки руководства (25,2 \%); непонимание цифровых трендов $(22,6 \%)$; неспособность вносить необходимые изменения в организационную культуру (20\%); неразвитость ИТ-инфраструктуры (20,0\%); недостаток специалистов по цифровым навыкам и знаниям (18,3\%); отсутствие баз данных $(3,5 \%)$; 


\section{Agricultural and Resource Economics \\ www.are-journal.com}

- организационная культура влияет на финансовые результаты предприятий: полностью (65,2 \% опрошенных) или частично $(24,4 \%)$;

- организационная культура предприятий в первую очередь влияет на увеличение объемов реализации продукции за счет повышения качества логистического сервиса $(38,3 \%$ респондентов $)$; повышение уровня прибыльности (32,2\%); сокращение затрат и, соответственно, себестоимости $(27,8 \%)[64]$.

Для оценки и выбора оптимального направления трансформации организационной культуры предприятий предлагается использовать метод анализа иерархий (метод Т. Саати), который позволяет количественно определить важность критериев и учитывает особенности и влияние экзогенных и эндогенных факторов на развитие организационной культуры предприятий. В результате проведенных расчетов доказано, что оптимальным направлением модернизации организационной культуры обследованных предприятий является внедрение цифровых технологий, которые позволят оптимизировать бизнес-процессы, поскольку оно имеет наибольшую эффективность $(0,401)$ по сравнению с другими двумя направлениями: повышение квалификации сотрудников, которая будет отвечать современным требованиям функционирования компаний; применение клиентоориентированного подхода к формированию и развитию организационной культуры предприятий, то есть ориентация компании на потребителей.

Это подтверждается и результатами экспертного опроса специалистов ряда украинских предприятий. Выявлено, что на обследованных предприятиях необходима частичная $(48,7 \%$ респондентов $)$ или полная $(39,1 \%)$ трансформация организационной культуры. По их мнению, модернизация организационной культуры должна заключаться в [61]:

- повышении квалификации сотрудников $(51,3 \%)$;

- внедрении цифровых технологий для оптимизации бизнес-процессов $(43,5 \%)$;

- повышении эффективности коммуникаций между сотрудниками, увеличении финансирования, устранении бюрократической составляющей при организации бизнес-процессов на предприятиях $(2,6 \%)$. При этом несмотря на то, что клиентоориентированный подход является ключевым направлением деятельности предприятий, только 20,0\% экспертов отметили о целесообразности трансформации системы управления взаимоотношениями с потребителями.

Исходя из вышеизложенного, установлено, что эффективному развитию организационной культуры в условиях цифровой экономики препятствует множество барьеров, которые условно можно систематизировать по 7 группам (табл. 3).

В условиях цифровой экономики успешное развитие организационной культуры в компаниях можно достичь, придерживаясь следующих принципов: 


\section{Agricultural and Resource Economics \\ www.are-journal.com}

сотрудники и команды работают на достижение результатов: они привержены своей работе, целям и задачам организации, готовы сделать все необходимое для достижения цели; сотрудники и команды работают так, чтобы продвигать стратегию предприятия; организационная среда (лидерство, организационные дизайн, управление эффективностью, методы развития персонала, ресурсы и инструменты, видение и ценности, неформальное взаимодействие) настраивается на стимулирование взаимодействия и поощрение поведения, которое будет реализовывать корпоративную стратегию развития [48].

Таблицуа 3

\section{Систематизация барьеров, которые сдерживают успешное развитие организационной культуры предприятий}

\begin{tabular}{|c|c|}
\hline Барьеры & Содержание \\
\hline Кадровые & $\begin{array}{l}\text { - отсутствие цифровой стратегии управления персоналом компании; } \\
\text { игнорирование необходимости культурных изменений } \\
\text { - низкий уровень вовлеченности сотрудников } \\
\text { - недостаток квалифицированных и компетентных кадров в условиях } \\
\text { глобальных экономических преобразований }\end{array}$ \\
\hline Информационные & 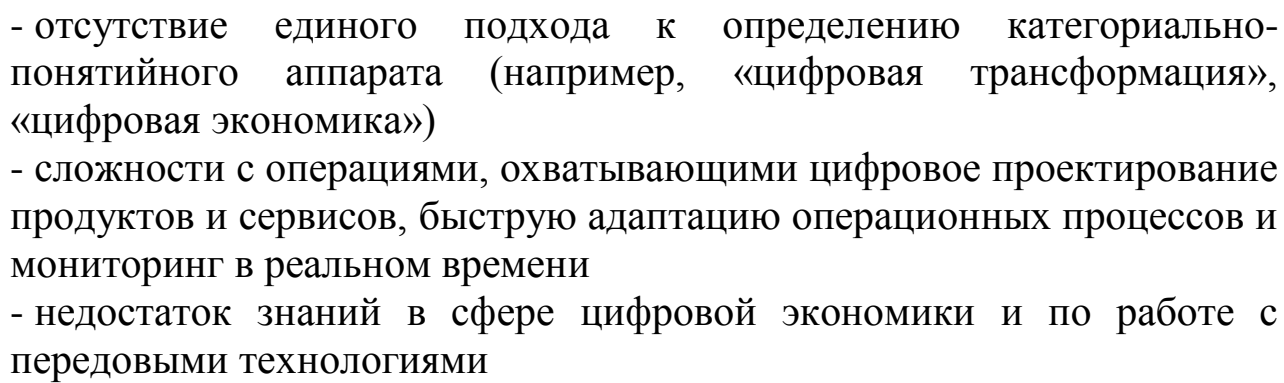 \\
\hline Организа & $\begin{array}{l}\text { - отсутствие четко определенной стратегии цифровой трансформации, } \\
\text { видения цифрового будущего компании и недостатки руководства; } \\
\text { неумение управлять организационными изменениями } \\
\text { - отсутствие «разумного» подхода к управлению рисками при цифровой } \\
\text { трансформации бизнес-процессов (т.е. низкий уровень цифровой } \\
\text { готовности функций управления рисками к цифровой трансформации) }\end{array}$ \\
\hline Марк & $\begin{array}{l}\text { - неэффективное использование инструментов корпоративных } \\
\text { коммуникаций } \\
\text { - отсутствие общепринятого понятия «клиентоориентированность»; } \\
\text { недостаточное применение клиентоориентированного подхода к } \\
\text { формированию организационной культуры предприятий }\end{array}$ \\
\hline Образов & $\begin{array}{l}\text { - кросс-функциональные барьеры в знаниях руководителей бизнеса и } \\
\text { ИТ-специалистов, то есть недостаточное применение } \\
\text { межфункционального подхода, предполагающего владение знаниями } \\
\text { в области разработки стратегии и ее реализации и необходимыми } \\
\text { технологическими знаниями и навыками } \\
\text { - дефицит цифровых навыков и квалификации у персонала }\end{array}$ \\
\hline Технологические & - архаичные ИТ-системы и приложения \\
\hline $\begin{array}{l}\text { Инвестиционно- } \\
\text { финансовые }\end{array}$ & $\begin{array}{l}\text { - недостаточный } \text { объем } \quad \text { инвестиций } \\
\text { (Интернет вещей, искусственный интеллект, блокчейн и т.д.) }\end{array}$ \\
\hline
\end{tabular}

Источник: авторская разработка.

Основными компонентами организационной культуры в цифровой 


\section{Agricultural and Resource Economics \\ www.are-journal.com}

экономике являются цифровые навыки и компетенции, тип мышления и поведение, деловые отношения и источники профессиональных знаний, модели развития карьеры (рис. 2).

взаимодействие «человек - машина»; переход к гибким методам работы; данные и аналитика;

мультикомпетентное взаимодействие;

технологические навыки;

цифровой IQ;

кодирование скорость; новая цель и методы работы; цифровой тип мышления и видение; ориентация на решение проблем; креативность и новаторство; оперативность в принятии решений; новые стили лидерства; предпринимательский потенциал; делегирование полномочий

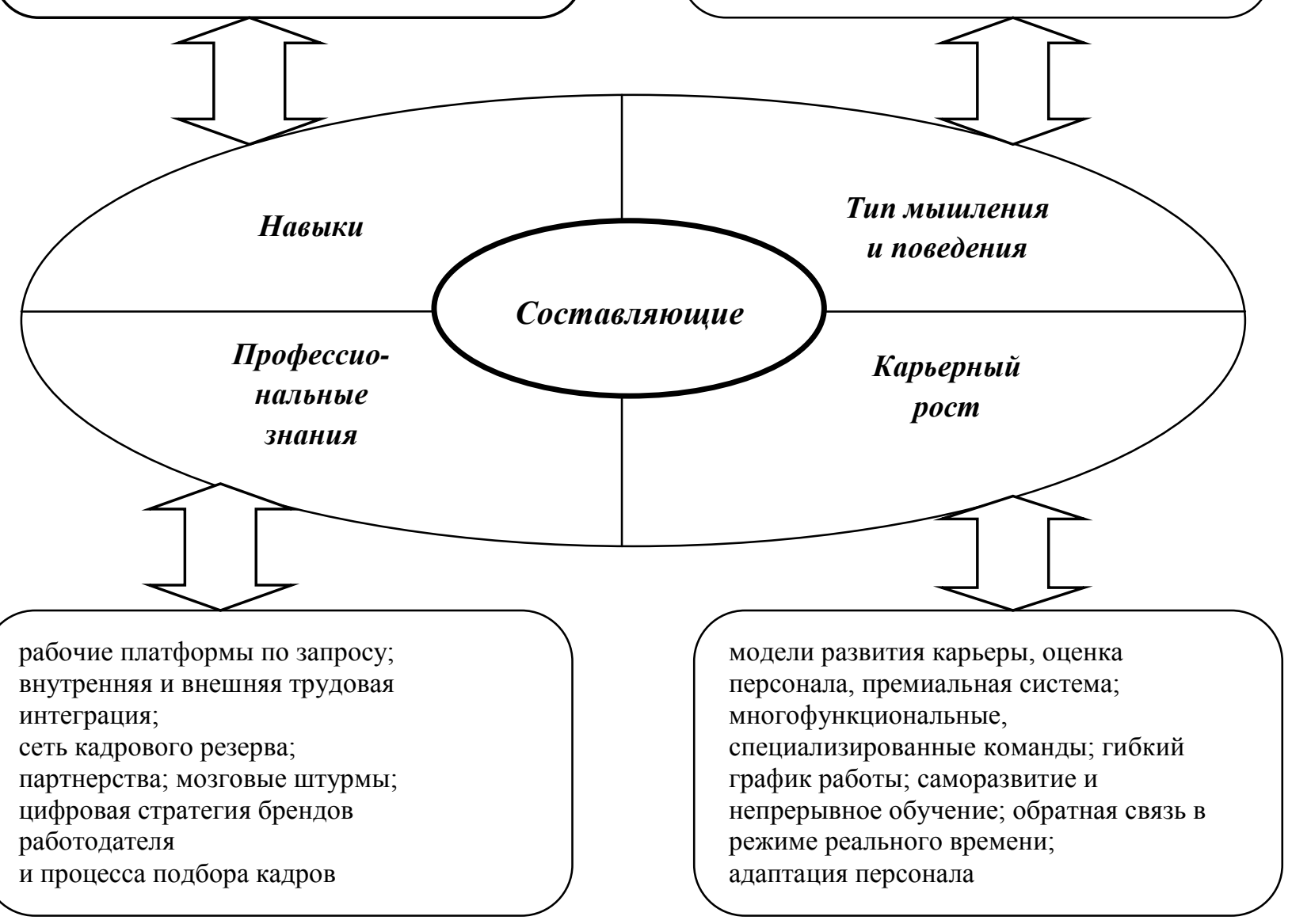

\section{Рис. 2. Содержательная структура организационной культуры в эпоху} цифровых трансформаций

Источник: авторская разработка.

При этом к специфическим особенностям цифровой культуры предприятий можно отнести:

- применение клиентоориентированного подхода к логистическому обслуживанию потребителей в контексте маркетинга взаимоотношений;

- делегирование полномочий;

- управление рисками в системе риск-менеджмента предприятий;

- больше действий, а планирование уходит на второй план;

- сотрудничество ценится выше, чем индивидуальные усилия - успех происходит благодаря коллективной работе и обмену информацией между департаментами, функциями. Итеративный и быстрый темп цифровой работы 


\section{Agricultural and Resource Economics \\ www.are-journal.com}

требует гораздо более высокого уровня прозрачности и взаимодействия.

Для повышения эффективности развития организационной культуры предприятий в контексте цифровой экономики целесообразно внедрять комплексный подход, сущность которого состоит в симбиозе и постоянной взаимосвязи факторов влияния, составляющих элементов, цифровых компетенций и навыков, информационных технологий (рис. 3).

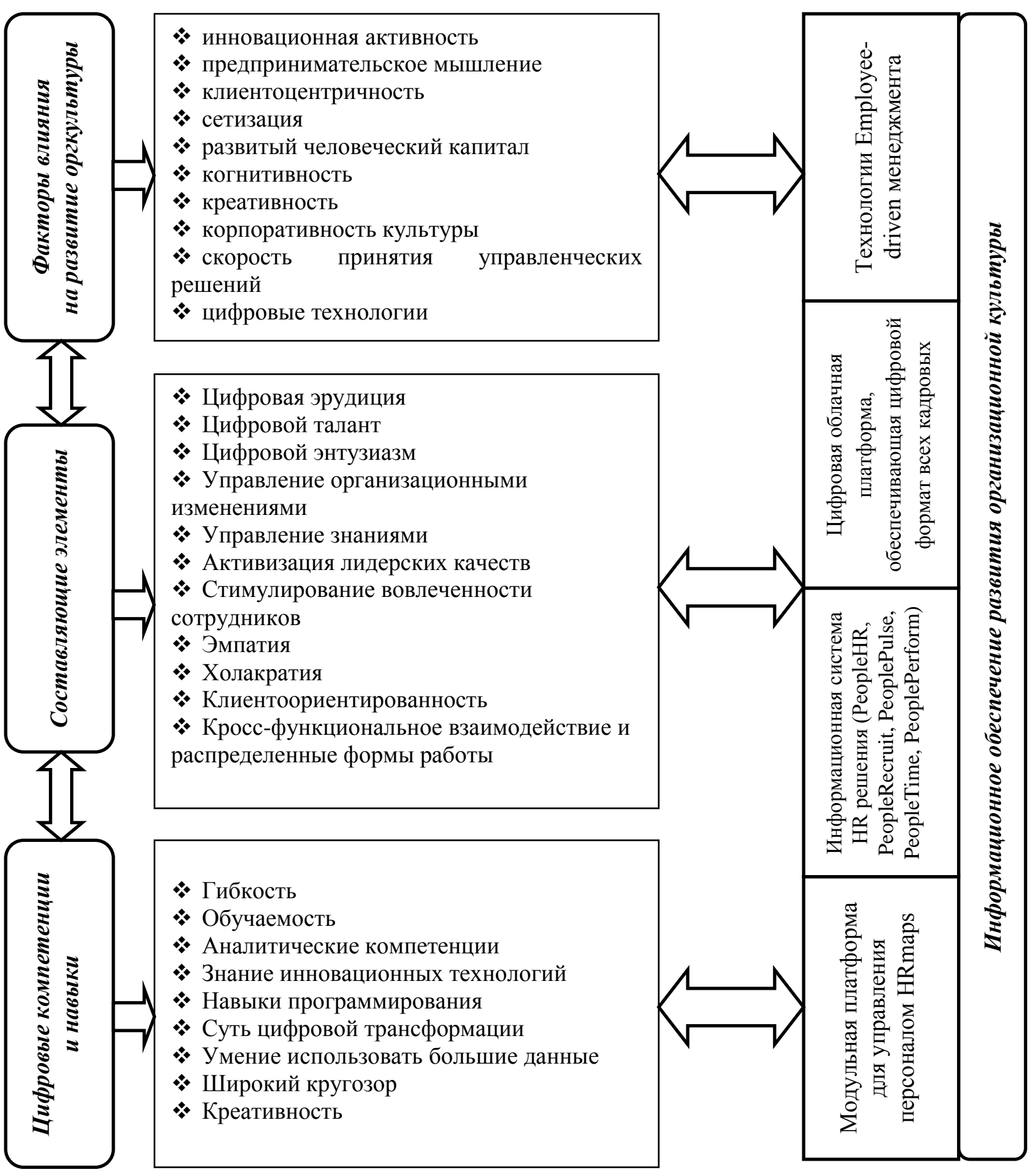

Рис. 3. Комплексный подход к модернизации организационной культуры предприятий в эпоху цифровых преобразований

Источник: авторская разработка. 


\section{Agricultural and Resource Economics}

www.are-journal.com

Модульная платформа для управления персоналом HRmaps - комплексное решение для автоматизации HR-процессов, состоящее из 4 модулей и HRпортала:

- оценка персонала (Measure) - модуль позволяет выполнять разные виды оценок: по компетенциям, целям, КРI; ежегодная оценка, регулярные собеседования, опросы и тесты;

- подбор и адаптация (Attract) - способствует управлению процессом подбора персонала, от появления вакансии до адаптации на новом рабочем месте;

- планирование и карьера (Plan) - позволяет составлять планы развития карьеры, преемственности, управлять потенциалами и мобильностью;

- обучение и развитие (Succeed) - модуль позволяет формировать планы учебных мероприятий, записываться и проходить обучение, осуществлять контроль.

Внедрение этой платформы необходимо для HR-специалиста для оптимизации и автоматизации рутинных кадровых процессов; руководителя компании - для повышения эффективности и производительности сотрудников; владельца бизнеса - для повышения контроля над компанией и роста прибыльности за счет быстрого достижения целей.

Реализация информационной системы HRmaps способствует централизации информации для надежного хранения данных; автоматизации трудоемких административных задач; ускорению и упрощению процессов рекрутинга и интеграции; формированию системы управления талантами; повышению эффективности выполняемых задач по управлению персоналом.

Информационная система HR решения позволяет автоматизировать HRпроцессы, централизовать всю информацию в одном месте, удерживать лучшие таланты, ускорять процессы найма, оценивать производительность, осуществлять коллаборацию между сотрудниками, отслеживать вовлеченность сотрудников. Эта система включает:

- PeopleHR - централизация и решение всех HR-задач обеспечивая прозрачность внутри компании;

- PeopleRecruit - система для подбора персонала, которая помогает найти лучшие таланты в 2 раза быстрее;

- PeoplePulse - создание и планирование опросов для мониторинга и анализа вовлеченности и удовлетворенности;

- PeopleTime - отслеживание времени на каждый из проектов и анализ статистики по агрегированным отчетам;

- PeoplePerform - отслеживание эффективности и прогресса сотрудников с помощью целей и задач.

Реализация предложений по модернизации организационной культуры предприятий в эпоху цифровых преобразований позволит получить эффект в результате:

- снижения в 2 раза времени на трудоемкие процессы по управлению 


\section{Agricultural and Resource Economics}

www.are-journal.com

персоналом;

- повышения уровня вовлеченности сотрудников в процесс цифровизации на $38 \%$;

- оптимизации управления компетенциями и навыками;

- ускорения запуска новых цифровых решений на 33 \%;

- повышения производительности сотрудников за счет реализации клиентоориентированного подхода;

- снижения рисков при подборе персонала;

- повышения уровня обслуживания потребителей и качества логистического сервиса;

- увеличения количества квалифицированных сотрудников;

- роста средней заработной платы сотрудников компании из-за оптимизации административных затрат;

- сокращения затрат на: адаптацию и обучение; аттестацию персонала; управление персоналом на основе автоматизации и оптимизации HR-процессов до $90 \%$; за счет эффективного распределения человеческих ресурсов и рационального инвестирования в развитие сотрудников.

Выводы. Интенсивное развитие цифровой экономики оказывает значительное влияние на все сферы деятельности предприятий, в том числе и на развитие организационной культуры. Это подтверждает и сравнительный анализ существующих методик оценки цифровой зрелости и трансформации бизнес-процессов на предприятиях, разработанных международными компаниями, аналитическими и научно-исследовательскими центрами.

Расчеты с помощью метода анализа иерархий показали, что оптимальным вариантом модернизации организационной культуры обследованных предприятий является внедрение цифровых технологий, которые позволят оптимизировать бизнес-процессы, поскольку он имеет наибольшую эффективность по сравнению с другими направлениями. Это обнаружено и в ходе опроса экспертов, по мнению которых трансформация организационной культуры компаний должна заключаться в повышении квалификации сотрудников $(51,3 \%)$, внедрении цифровых технологий для оптимизации бизнес-процессов $(43,5 \%)$ и ориентация на клиентов (20\%). Однако на обследованных предприятиях не уделяется должного внимания применению клиентоориентированного подхода к формированию организационной культуры, что признано одним из приоритетных направлений на современном этапе.

Установлено, что успешному развитию организационной культуры в цифровой экономике препятствует множество барьеров, которые условно можно систематизировать по семи группам: информационные, организационные, кадровые, маркетинговые, образовательные, технологические, инвестиционно-финансовые.

Следует отметить, что эффективная цифровая трансформация возможна на тех предприятиях, где руководители занимаются формированием цифровой 


\section{Agricultural and Resource Economics}

www.are-journal.com

культуры, снижают барьеры для общения между всеми подразделениями и налаживают двустороннюю связь между низшими и высшими звеньями. Цифровая трансформация должна осуществляться за счет тщательной внутренней работы по информированию всех сотрудников и изучения уровня их организационной культуры. Для того, чтобы все сотрудники компании понимали цели цифровой трансформации, следует проводить работу по обучению персонала, реализовывать внеплановое повышение квалификации сотрудников, учебные курсы и тренинги.

При этом важным является инвестирование в образование и обучение сотрудников, поскольку развитие цифровых знаний персонала признано предпосылкой для эффективной цифровизации бизнес-процессов компаний. Руководители предприятий должны разрабатывать и реализовывать программы обучения цифровых навыков персонала, используя возможности и концепции дистанционного обучения, в партнерстве с академическими учреждениями, высшими учебными заведениями и инновационными стартапами, а также формировать организационную культуру, в которой поощряют и признают обучение и повышение квалификации. Устранение разрыва между необходимыми специальными цифровыми навыками и теми, что имеет персонал компании, должно стать основным средством успешных трансформационных преобразований в глобальном информационном пространстве.

Применение цифровых технологий позволит сократить расходы на управление персоналом в результате снижения уровня рисков при подборе персонала, эффективного распределения человеческих ресурсов, автоматизации и оптимизации HR-процессов, рационального инвестирования в саморазвитие сотрудников, и тем самым сформировать успешную цифровую культуру, соответствующую современных условиям хозяйствования. Результаты исследования могут быть использованы публичными агропромышленными компаниями. В дальнейших исследованиях необходимо уделить внимание разработке маркетинговой информационной системы управления развитием организационной культуры предприятий в условиях цифровой экономики.

\section{Список использованных источников}

1. Кокорев А. С. Цифровая экономика: смена ценностей и ориентиров в управлении предприятием. Московский экономический журнал. 2019. № 1. C. 252-259. https://doi.org/10.24411/2413-046X-2019-11028.

2. Industry 4.0 at McKinsey's model factories. Get ready for the disruptive wave. 2016. URL: http://sf-eu.net/wp-content/uploads/2016/08/mckinsey-2016industry-4.0-at-mckinseys-model-factories-en.pdf.

3. Byrd T. A., Turner D. E. An exploratory analysis of the value of the skills of IT personnel: Their relationship to IS infrastructure and competitive advantage. Decision Sciences. 2001. Vol. 32. No. 1. Pp. 21-47. https://doi.org/10.1111/j.15405915.2001.tb00952.x.

4. Johannsen W., Goeken M. IT-Governance - neue Aufgaben des IT- 


\section{Agricultural and Resource Economics}

www.are-journal.com

Managements. HMD - Praxis Der Wirtschaftsinformatik. 2006. Vol. 250. Pp. 7-20.

5. Kiessling M., Wilke H., Kolbe L. M. Overcoming challenges for managing IT innovations in non-IT companies. Proceedings of the 16th Americas Conference on Information Systems (August 12-15, 2010). Lima: Curran Associates, Inc. 2010. Pp. 1-9.

6. Nissen V., Lezina T., Saltan A. The Role of IT-Management in the Digital Transformation of Russian Companies. Foresight and STI Governance. 2018 Vol. 12, No. 3. Pp. 53-61. https://doi.org/10.17323/2500-2597.2018.3.53.61.

7. Bhattacharya P. J., Seddon P. B. Role of Enterprise Systems in Business Transformations: A Management Perspective. Proceedings of the 20th Australasian Conference on Information Systems (2-4 December 2009). Melbourne: Monash University, 2009. Pp. 278-289.

8. Bharadwa A., Sawy O. A., Pavlou P. A., Venkatraman N. Digital business strategy: Toward a next generation of insights. MIS Quarterly. 2013. Vol. 37. No. 2. Pp. 471-482. https://doi.org/10.25300/MISQ/2013/37:2.3.

9. Haes S., van Grembergen W. An Exploratory Study into IT-Governance Implementations and its Impact on Business/IT Alignment. Information Systems Management. 2009. Vol. 26. $\quad$ No. 2. $\quad$ Pp. 123-137. https://doi.org/10.1080/10580530902794786.

10. Kane G. C., Palmer D., Philips N. A., Kiron D., Buckley N. Strategy, Not Technology, Drives Digital Transformation. Becoming a Digitally Mature Enterprise. Cambridge, MA: MIT Sloan Management School, 2015. 80 p.

11. Bley K., Leyh C., Schäffer T. Digitization of German Enterprises in the Production Sector - Do they know how 'digitized' they are? Proceedings of the 22nd Americas Conference on Information Systems (August 11-14, 2016). San DiegoCalifornia: Association for Information Systems, 2016. Pp. 1-10.

12. Urbach N., Drews P., Ross J. W. Digital Business Transformation and the Changing Role of the IT Function. MIS Quarterly Executive. 2017. Vol. 16. No. 2. Pp. 1-4.

13. Weill P., Ross J. W. IT Governance: How Top Performers Manage IT Decisions Rights for Superior Results. Cambridge, MA: Harvard Business School Press, 2004. 127 p.

14. Hanschke I. Strategic IT-Management: A Toolkit for Enterprise Architecture Management. Berlin, Heidelberg: Springer-Verlag, 2010. 215 p. https://doi.org/10.1007/978-3-642-05034-3.

15. Стрелец И. А. Влияние новых технологий на экономическое поведение потребителей и фирм. США и Канада: экономика, политика, культура. 2008. № 8. С. 63-72.

16. Dearstyne B. E-Business, E-Government \& Information Proficiency. Information Management Journal. 2001. Vol. 35. No. 4. Pp. 17-23.

17. Nonaka I. The Knowledge-Creating Company. The Economic Impact of Knowledge / eds. D. Neef, G. A. Siesfeld, J. Cefola. New York: Oxford University Press, 1998.368 p. 
18. Kaplan R. S., Norton D. P. The Balanced Scorecard: Translating Strategy into Action. Boston: Harvard Business School Press, 1996. Pp. 4-6.

19. Denison D. R. Corporate culture and organizational effectiveness. New Jersey: John Wiley \& Sons, 1990. 242 p.

20. Yilmal C., Ergun E. Organizational culture and firm effectiveness: An examination of relative effects of culture trains and the balanced culture hypothesis in an emerging economy. Journal of World Business. 2008. Vol. 43. No. 3. Pp. 290306. https://doi.org/10.1016/j.jwb.2008.03.019.

21. Millington M. J. Schultz J. C. The Challenge of Organization Culture in Quality Assurance Implementation. Journal of Rehabilitation Administration. 2009. Vol. 33. Pp. 121-130.

22. Cameron K. S. Quinn R. E. Diagnosing and Changing Organizational Culture: Based on the Competing Values Framework. 3rd ed. New Jersey: John Wiley \& Sons, 2011.288 p.

23. Hofstede G. Dimensionalizing Cultures: The Hofstede Model in Context. Online Readingsin Psycology and Culture. 2011. Vol. 2. No. 1. Pp. 1-7. https://doi.org/10.9707/2307-0919.1014.

24. Dwivedi S., Kaushik S., Luxmi. Impact of Organizational Culture on Commitment of Employees: An Empirical Study of BPO Sector in India. Vikalpa. 2014. Vol. 39. Is. 3. Pp. 77-92. https://doi.org/10.1177/0256090920140306.

25. Lapina I., Kairisa I., Aramina D. Role of Organizational Culture in the Quality Management of University. Procedia-Social and Behavioral Sciences. 2015. Vol. 213. Pp. 770-774. https://doi.org/10.1016/j.sbspro.2015.11.472.

26. Ahmady G. A., Nikooravesh A., Mehrpour M. Effect of Organizational Culture on Knowledge Management Based on Denison Model. Procedia-Social and Behavioral Sciences. 2016. $\quad$ Vol. $230 . \quad$ Pp. 387-395. https://doi.org/10.1016/j.sbspro.2016.09.049.

27. Nam Y., Kim H. A Study on the Effect of Industry Organizational Culture on Job Attitude of Organizational Employees - Comparison between the Semiconductor and the Automobile Industries. Procedia Computer Science. 2016. Vol. 91. Pp. 581-590. https://doi.org/10.1016/j.procs.2016.07.149.

28. Arditi D., Nayak S., Damci A. Effect of organizational culture on delay in construction. International Journal of Project Management. 2017. Vol. 35. Is. 2. Pp. 136-147. https://doi.org/10.1016/j.ijproman.2016.10.018.

29. Dźwigoł H. Business management - compendium. Oxford: Alpha Science International Ltd, 2017. 178 p.

30. Dźwigoł $\mathrm{H}$. Organizational structure within the process of organization management. Marketing i Rynek. 2017. Nr. 24(7). Pp. 171-183.

31. Dźwigoł H. Research methods and techniques in new management trends: research results. Virtual Economics. 2019. Vol. 2. No. 1. Pp. 31-48. https://doi.org/10.34021/ve.2019.02.01(2).

32. Kwilinski A. Mechanism of modernization of industrial sphere of industrial enterprise in accordance with requirements of the information economy. Marketing 


\section{Agricultural and Resource Economics}

www.are-journal.com

and Management of Innovations. 2018. Vol.4. Pp. 116-128.
https://doi.org/10.21272/mmi.2018.4-11.

33. Kwilinski A. Mechanism of formation of industrial enterprise development strategy in the information economy. Virtual Economics. 2018. Vol. 1. No. 1. Pp. $7-$ 25. https://doi.org/10.34021/ve.2018.01.01(1).

34. Kwilinski A. Implementation of Blockchain Technology in Accounting Sphere. Academy of Accounting and Financial Studies Journal. 2019. Vol. 23(SI2). Pp. 1-6.

35. Dasgupta S., Gupta B. Espoused organizational culture values as antecedents of internet technology adoption in an emerging economy. Information \& Management. 2019. Vol. 56. Is. 6. 103143. https://doi.org/10.1016/j.im.2019.01.004.

36. Suryaningtyas D., Sudiro A., Troena E. A., Irawanto D. W. Organizational resilience and organizational performance: examining the mediating roles of resilient leadership and organizational culture. Academy of Strategic Management Journal. 2019. Vol. 18. Is. 2. Pp. 1-7.

37. Tortorella G. L., Vergara A. M. C., Garza-Reyes J. A., Sawhney R. Organizational learning paths based upon industry 4.0 adoptions: An empirical study with Brazilian manufacturers. International Journal of Production Economics. 2019. Vol. 219. Pp. 284-294. https://doi.org/10.1016/j.ijpe.2019.06.023.

38. Martinez-Caro E., Cegarra-Navarro J. G., Alfonso-Ruiz F. J. Digital technologies and firm performance: The role of digital organizational culture. Technological Forecasting and Social Change. 2020. Vol. 154.119962. https://doi.org/10.1016/j.techfore.2020.119962.

39. Upadhyay P., Kumar A. The intermediating role of organizational culture and internal analytical knowledge between the capability of big data analytics and a firm's performance. International Journal of Information Management. 2020. Vol. 52. 102100. https://doi.org/10.1016/j.ijinfomgt.2020.102100.

40. Veiga A., Astakhova L. V., Botha A., Herselman M. Defining organizational information security culture - Perspectives from academia and industry. Computers \& Security. 2020. Vol. 92. 101713. https://doi.org/10.1016/ j.cose.2020.101713.

41. Галимова М. П. Готовность российских предприятий к цифровой трансформации: организационные драйверы и барьеры. Вестник УГНТУ. Наука, образование, экономика. Сер.: Экономика. 2019. № 1(27). С. 27-37. https://doi.org/10.17122/2541-8904-2019-1-27-27-37.

42. Autio E., Szerb L., Komlósi E., Tiszberger M. The European Index of Digital Entrepreneurship Systems. Luxembourg: Publications Office of the European Union, 2018. 154 p. https://doi.org/10.2760/39256.

43. Kostoulas J. Digital Business Redefines Talent Management Applications. 2018. URL: https://www.gartner.com/en/documents/3852273/digital-businessredefines-talent-management-application0.

44. Engert O., Kaetzler B., Kordestani K., MacLean A. Organizational Culture in mergers: Addressing the unseen forces. New York: McKinsey\&Company, 2019. Pp. 1-7. 


\section{Agricultural and Resource Economics}

www.are-journal.com

45. Digital Business Transformation. A Conceptual Framework. Global Center for Digital Business Transformation, 2015. $16 \mathrm{p}$. URL: https:// ru.scribd.com/document/ 372049639/DigitalBusiness-Transformation-Frameworkpdf.

46. The Microsoft Digital Transformation Series. Part 1: The Digital Transformation Opportunity. Aligning Business Strategy to the Digital Transformation Market Opportunity, 2016. URL: https://assetsprod.microsoft.com/mpn/en-us/digital-transformation-opportunity.

47. The Digital Advantage: how digital leaders outperform their peers in every industry, 2017. 24 p. URL: https://www.capgemini.com/wpcontent/uploads/2017/07/The_Digital_Advantage_How_Digital_Leaders_Outperfor m_their_Peers_in_Every_Industry.pdf.

48. Hemerling J., Kilmann J., Danoesastro M., Stutts L., Ahern C. It's not a digital transformation without a digital culture. Boston, Massachusetts: BCG, 2018. $24 \mathrm{p}$.

49. Савич Ю. А. Цифровая трансформация и ее влияние на конкурентоспособность промышленных предприятий. ЭкономИНФО. 2018. T. 15. № 4. C. 44-48.

50. Гилева Т. А. Цифровая зрелость предприятия: методы оценки и управления. Вестник УГНТУ. Наука, образование, экономика. Сер.: Экономика. 2019. № 1(27). C. 38-52. https://doi.org/10.17122/2541-8904-2019-1-27-38-52.

51. CGI Global 1000. Insights from Conversations with Business and IT Executives around the World. 2016. URL: https://www. cginederland.nl/sites/default/ files/files_nl/articles/cgi-nl_presentatie_cgi-global-1000.pdf.

52. Hoberg P., Krcmar H., Welz B. Skills for Digital Transformation. Research Report 2017. Garching: Technical University of Munich, 2017. 10 p.

53. Global CIO survey: UK edition. Manifesting legacy: Looking beyond the digital era. URL: https://www2.deloitte.com/uk/en/pages/technology/ articles/ciosurvey.html.

54. Implications of Disruptive Technologies on Professional Services Organizations. Russell Reynolds Associates', 2018. 12 p. URL: https://www.russellreynolds.com/en/Insights/thought-leadership/Documents/RRA__Implications_of_Disruptive_Technologies_on_Professional_Services.pdf.

55. Рыжков В., Чернов Е., Нефедова О., Тарасова В. Цифровая трансформация в России: аналит. отчет. Москва: ООО «Команда-А Менеджмент», 2018. 32 с.

56. Исследование Oliver Wyman. Корпоративная культура в России: новые горизонты трансформации. Москва: Oliver Wyman, 2019. 29 с.

57. Исследование Coleman Services. Функции HR: актуальные задачи, приоритеты, вызовы. URL: https://www.coleman.ru/getattachment/e6d4f0ae-927a4e5b-ae28-dddc56135caa/HR-

\%D1\%84\%D1\%83\%D0\%BD\%D0\%BA\%D1\%86\%D0\%B8\%D0\%B8_2019.pdf.

58. The Digital Culture Challenge: Closing the Employee-Leadership Gap. 


\section{Agricultural and Resource Economics}

www.are-journal.com

2017. Capgemini $\quad$ Consulting, $2017 . \quad 31 \mathrm{p} . \quad$ URL:

https://www.capgemini.com/consulting/wpcontent/uploads/sites/30/2017/07/dti_digitalculture_report.pdf.

59. Глобальное исследование цифровых операций в 2018 г. «Цифровые чемпионы». Как лидеры создают интегрированные операционные экосистемы для разработки комплексных решений для потребителей. Москва: $\mathrm{PwC}, 2018$. 64 c. URL: https://www.pwc.ru/ru/iot/digital-champions.pdf.

60. Kane G. C., Palmer D., Philips N. A., Kiron D., Buckley N. Aligning the Organization for its Digital Future. Cambridge, MA: MIT Sloan Management Review, Deloitte University Press, 2016. 47 p.

61. Ринкевич Н. Розвиток організаційної культури в системі менеджменту підприємств харчової промисловості. Agricultural and Resource Economics. 2020. Vol. 6. No. 1. Pp. 123-145. URL: http://are-journal.com.

62. Трушкіна Н. В., Ринкевич Н. С. Методичний підхід до оцінювання рівня розвитку організаційної культури підприємств. Причорноморські економічні студіï. 2019. Вип. 48-2. С. 112-118. https://doi.org/10.32843/bses.4851.

63. Трушкина Н. В., Рынкевич Н. С. Клиентоориентированность: основные подходы к определению. Бізнес Інформ. 2019 . № 8. С. 244-252. https://doi.org/10.32983/2222-4459-2019-8-244-252.

64. Трушкіна Н. В., Ринкевич Н. С. Цифрова трансформація організаційної культури підприємств: особливості, бар'єри та драйвери. Сучасні прочеси трансформації у бізнесі та виробництві: теорія, методологія, практика (зовнішньоекономічна діяльність, промислове виробництво та транспорт): монографія / за ред. Л. М. Савчук, Л. М. Бандоріної. Дніпро: Пороги, 2019. C. 340-350.

\section{References}

1. Kokorev, A. S. (2019), Digital economy: changing values and guidelines in enterprise management. Moscow Journal of Economics, no. 1, pp. 252-259. https://doi.org/10.24411/2413-046H-2019-11028.

2. Industry 4.0 at McKinsey's model factories. Get ready for the disruptive wave (2016), available at: http://sf-eu.net/wp-content/uploads/2016/08/mckinsey-2016industry-4.0-at-mckinseys-model-factories-en.pdf.

3. Byrd, T. A. and Turner, D. E. (2001), An exploratory analysis of the value of the skills of IT personnel: Their relationship to IS infrastructure and competitive advantage. Decision Sciences, vol. 32, no. 1, pp. 21-47. https://doi.org/10.1111/j.1540-5915.2001.tb00952.x.

4. Johannsen, W. and Goeken, M. (2006), IT-Governance - neue Aufgaben des IT-Managements. HMD - Praxis Der Wirtschaftsinformatik, vol. 250, pp. 7-20.

5. Kiessling, M., Wilke, H. and Kolbe, L. M. (2010), Overcoming challenges for managing IT innovations in non-IT companies. Proceedings of the 16th Americas Conference on Information Systems (August 12-15, 2010). Curran Associates, Inc., 
Lima, Peru.

6. Nissen, V., Lezina, T. and Saltan, A. (2018), The Role of IT-Management in the Digital Transformation of Russian Companies. Foresight, vol. 12, no. 3, pp. 5361. https://doi.org/10.17323/2500-2597-2018.3.53.61.

7. Bhattacharya, P. J. and Seddon, P. B. (2009), Role of Enterprise Systems in Business Transformations: A Management Perspective. Proceedings of the 20th Australasian Conference on Information Systems (2-4 December 2009), Monash University, Melbourne, Australia.

8. Bharadwa, A., Sawy, O. A., Pavlou, P. A. and Venkatraman, N. (2013), Digital business strategy: Toward a next generation of insights. MIS Quarterly, vol. 37, no. 2, pp. 471-482. https://doi.org/10.25300/MISQ/2013/37:2.3.

9. Haes, S., and van Grembergen, W. (2009), An Exploratory Study into ITGovernance Implementations and its Impact on Business/IT Alignment. Information Systems Management, vol. 26, no. 2, pp. 123-137. https://doi.org/10.1080/10580530902794786.

10. Kane, G. C., Palmer, D., Philips, N. A., Kiron, D. and Buckley, N. (2015), Strategy, Not Technology, Drives Digital Transformation. Becoming a Digitally Mature Enterprise. MIT Sloan Management School, Cambridge, UK.

11. Bley, K., Leyh, C. and Schäffer, T. (2016), Digitization of German Enterprises in the Production Sector - Do they know how 'digitized' they are? Proceedings of the 22nd Americas Conference on Information Systems (August 1114, 2016). Association for Information Systems, San Diego, California, USA.

12. Urbach, N., Drews, P. and Ross, J. W. (2017), Digital Business Transformation and the Changing Role of the IT Function. MIS Quarterly Executive, vol. 16 , no. 2 , pp. 1-4.

13. Weill, P., and Ross, J. W. (2004), IT Governance: How Top Performers Manage IT Decisions Rights for Superior Results. Harvard Business School Press, Cambridge, MA, UK.

14. Hanschke, I. (2010), Strategic IT-Management: A Toolkit for Enterprise Architecture Management. Heidelberg: Springer-Verlag, Berlin, Germany. https://doi.org/10.1007/978-3-642-05034-3.

15. Strelec, I. A. (2008), The impact of new technologies on the economic behavior of consumers and firms. USA and Canada: Economics, Politics, Culture, vol. 8, pp. 63-72.

16. Dearstyne, B. (2001), E-Business, E-Government \& Information Proficiency. Information Management Journal, vol. 35, no. 4, pp. 17-23.

17. Nonaka, I. (1998), The Knowledge-Creating Company in The Economic Impact of Knowledge, eds. D. Neef, G. A. Siesfeld, J. Cefola. Oxford University Press, New York, USA.

18. Kaplan, R. S. and Norton, D. P. (1996), The Balanced Scorecard: Translating Strategy into Action. Harvard Business School Press, Boston, USA.

19. Denison, D. R. (1990), Corporate culture and organizational effectiveness. John Wiley \& Sons, New Jersey, USA. 
20. Yilmal, C. and Ergun, E. (2008), Organizational culture and firm effectiveness: An examination of relative effects of culture trains and the balanced culture hypothesis in an emerging economy. Journal of World Business, vol. 43, no. 3, pp. 290-306. https://doi.org/10.1016/j.jwb.2008.03.019.

21. Millington, M. J. and Schultz, J. C. (2009), The Challenge of Organization Culture in Quality Assurance Implementation. Journal of Rehabilitation Administration, vol. 33, pp. 121-130.

22. Cameron, K. S. and Quinn, R. E. (2011), Diagnosing and Changing Organizational Culture: Based on the Competing Values Framework. 3rd ed. John Wiley \& Sons, New Jersey, USA.

23. Hofstede, G. (2011), Dimensionalizing Cultures: The Hofstede Model in Context. Online Readingsin Psycology and Culture, vol. 2, no. 1, pp.1-7. https://doi.org/10.9707/2307-0919.1014.

24. Dwivedi, S., Kaushik, S. and Luxmi (2014), Impact of Organizational Culture on Commitment of Employees: An Empirical Study of BPO Sector in India. Vikalpa, vol. 39, no. 3, pp. 77-92. https://doi.org/10.1177/0256090920140306.

25. Lapina, I., Kairisa, I. and Aramina, D. (2015), Role of Organizational Culture in the Quality Management of University. Procedia-Social and Behavioral Sciences, vol. 213, pp. 770-774. https://doi.org/10.1016/j.sbspro.2015.11.472.

26. Ahmady, G. A., Nikooravesh, A. and Mehrpour, M. (2016), Effect of Organizational Culture on Knowledge Management Based on Denison Model. Procedia-Social and Behavioral Sciences, vol.230, pp.387-395. https://doi.org/10.1016/j.sbspro.2016.09.049.

27. Nam, Y. and Kim, H. (2016), A Study on the Effect of Industry Organizational Culture on Job Attitude of Organizational Employees - Comparison between the Semiconductor and the Automobile Industries. Procedia Computer Science, vol. 91, pp. 581-590. https://doi.org/10.1016/j.procs.2016.07.149.

28. Arditi, D., Nayak, S. and Damci, A. (2017), Effect of organizational culture on delay in construction. International Journal of Project Management, vol. 35, no. 2, pp. 136-147. https://doi.org/10.1016/j.ijproman.2016.10.018.

29. Dźwigoł, H. (2017), Business management - compendium. Alpha Science International Ltd, Oxford, UK.

30. Dźwigoł, H. (2017), Organizational structure within the process of organization management. Marketing i Rynek, no. 24(7), pp. 171-183.

31. Dźwigoł, H. (2019), Research methods and techniques in new management trends: research results. Virtual Economics, vol. 2, no. 1, pp.31-48. https://doi.org/10.34021/ve.2019.02.01(2).

32. Kwilinski, A. (2018), Mechanism of modernization of industrial sphere of industrial enterprise in accordance with requirements of the information economy. Marketing and Management of Innovations, vol. 4, pp. 116-128. https://doi.org/10.21272/mmi.2018.4-11.

33. Kwilinski, A. (2018), Mechanism of formation of industrial enterprise development strategy in the information economy. Virtual Economics, vol. 1, no. 1, 
pp. 7-25. https://doi.org/10.34021/ve.2018.01.01(1).

34. Kwilinski, A. (2019), Implementation of Blockchain Technology in Accounting Sphere. Academy of Accounting and Financial Studies Journal, vol. 23(SI2), pp. 1-6.

35. Dasgupta, S. and Gupta, B. (2019), Espoused organizational culture values as antecedents of internet technology adoption in an emerging economy. Information \& Management, vol. 56, no. 6, 103143. https://doi.org/10.1016/ j.im.2019.01.004.

36. Suryaningtyas, D., Sudiro, A., Troena, E. A. and Irawanto, D. W. (2019), Organizational resilience and organizational performance: examining the mediating roles of resilient leadership and organizational culture. Academy of Strategic Management Journal, vo. 18, no. 2, pp. 1-7.

37. Tortorella, G. L., Vergara, A. M. C., Garza-Reyes, J. A. and Sawhney, R. (2019), Organizational learning paths based upon industry 4.0 adoptions: An empirical study with Brazilian manufacturers. International Journal of Production Economics, vol. 219, pp. 284-294. https://doi.org/10.1016/j.ijpe.2019.06.023.

38. Martinez-Caro, E., Cegarra-Navarro, J. G. and Alfonso-Ruiz, F. J. (2020), Digital technologies and firm performance: The role of digital organizational culture. Technological Forecasting and Social Change, vol. 154, 119962. https://doi.org/10.1016/j.techfore.2020.119962.

39. Upadhyay, P. and Kumar, A. (2020), The intermediating role of organizational culture and internal analytical knowledge between the capability of big data analytics and a firm's performance. International Journal of Information Management, vol. 52, 02100. https://doi.org/10.1016/ j.ijinfomgt.2020.102100.

40. Veiga, A., Astakhova, L. V., Botha, A. and Herselman, M. (2020), Defining organizational information security culture - Perspectives from academia and $\begin{array}{lllll}\text { industry. } \quad \text { Computers } \& \text { Security, } & \text { vol. 92, } & 101713 .\end{array}$ https://doi.org/10.1016/j.cose.2020.101713.

41. Galimova, M. P. (2019), Readiness of Russian enterprises for digital transformation: organizational drivers and barriers. Bulletin of USNTU. Science, education, economy. Ser.: Economics, vol. 1, no. 27, pp. 27-37. https://doi.org/10.17122/2541-8904-2019-1-27-27-37.

42. Autio, E., Szerb, L., Komlósi, E., Tiszberger, M. (2018), The European Index of Digital Entrepreneurship Systems. Publications Office of the European Union, Luxembourg. https://doi.org/10.2760/39256.

43. Kostoulas, J. (2018), Digital Business Redefines Talent Management Applications, available at: https://www.gartner.com/en/documents/3852273/digitalbusiness-redefines-talent-management-application0.

44. Engert, O., Kaetzler, B., Kordestani, K., MacLean, A. (2019), Organizational Culture in mergers: Addressing the unseen forces. McKinsey\&Company, New York, USA.

45. Digital Business Transformation (2015), A Conceptual Framework. Global Center for Digital Business Transformation, available at: https:// ru.scribd.com/document/372049639/DigitalBusiness-Transformation-Framework- 
pdf.

46. The Microsoft Digital Transformation Series (2016), Part 1: The Digital Transformation Opportunity. Aligning Business Strategy to the Digital Transformation Market Opportunity, available at: https://assetsprod.microsoft. $\mathrm{com} / \mathrm{mpn} / \mathrm{en}$-us/digital-transformation-opportunity.

47. The Digital Advantage: how digital leaders outperform their peers in every industry (2017), available at: https://www.capgemini.com/wpcontent/uploads/2017/07/The_Digital_Advantage

How_Digital_Leaders_Outperform_their_Peers_in_Every_Industry.pdf.

48. Hemerling, J., Kilmann, J., Danoesastro, M., Stutts, L. and Ahern, C. (2018), It's not a digital transformation without a digital culture. BCG, Boston, Massachusetts, USA.

49. Savich, Yu. A. (2018), Digital transformation and its impact on the competitiveness of industrial enterprises. EconomINFO, vol. 15, no. 4, pp. 44-48.

50. Gileva, T. A. (2019), Digital maturity of an enterprise: assessment and management methods. Bulletin of USPTU. Science, education, economy. Ser.: Economics, vol. 1, no. 27, pp. 38-52. https://doi.org/10.17122/2541-8904-2019-1-2738-52.

51. CGI Global 1000 (2016), Insights from Conversations with Business and IT Executives around the World, available at: https://www. cginederland.nl/sites/default/ files/files_nl/articles/cgi-nl_presentatie_cgi-global-1000.pdf.

52. Hoberg, P., Krcmar, H. and Welz, B. (2017), Skills for Digital Transformation. Research Report 2017. Technical University of Munich, Garching, Germany.

53. Global CIO survey: UK edition (2018), Manifesting legacy: Looking beyond the digital era, available at: https://www2.deloitte.com/uk/en/pages/technology/ articles/cio-survey.html.

54. Implications of Disruptive Technologies on Professional Services Organizations (2018), available at: https://www.russellreynolds.com/en/Insights/thought-leadership/ Documents/RRA_Implications_of_Disruptive_Technologies_on_ProfessionalServices.pdf.

55. Ryzhkov, V., Chernov, E., Nefedova, O., Tarasova, V. (2018), Cifrovaja transformacija v Rossii: analiticheskij otchet [Digital Transformation in Russia: An Analytical Report], LLC Team-A Management, Moscow, Russia.

56. Research Oliver Wyman (2019), Korporativnaja kul'tura v Rossii: novye gorizonty transformacii [Corporate culture in Russia: new horizons of transformation]. Oliver Wyman, Moscow, Russia.

57. Research Coleman Services (2019), Funktsii HR: aktualnyie zadachi, prioritetyi, vyizovyi [HR functions: current tasks, priorities, challenges], available at: https://www.coleman.ru/getattachment/e6d4f0ae-927a-4e5b-ae28-dddc56135caa/HRфункции 2019.pdf.

58. The Digital Culture Challenge: Closing the Employee-Leadership Gap (2017), available at: https://www.capgemini.com/consulting/wp- 
www.are-journal.com

content/uploads/sites/30/2017/07/dti_digitalculture_report.pdf.

59. Global'noe issledovanie cifrovyh operacij v 2018 godu "Cifrovye chempiony. Kak lidery sozdajut integrirovannye operacionnye jekosistemy dlja razrabotki kompleksnyh reshenij dlja potrebitelej" [Global Digital Operations Survey Digital Champions. How leaders create integrated operational ecosystems to develop end-to-end consumer solutions], PwC, Moscow, Russia, available at: https://www.pwc.ru/ru/iot/digital-champions.pdf.

60. Kane, G. C., Palmer, D., Philips, N. A., Kiron, D. and Buckley, N. (2016), Aligning the Organization for its Digital Future. MIT Sloan Management Review, Deloitte University Press, Cambridge, MA, UK.

61. Rynkevich, N. (2020), Development of organizational culture in the management system of the food industry enterprises. Agricultural and Resource Economics, vol. 6, no. 1, pp. 123-145, available at: http://are-journal.com.

62. Trushkina, N. V. and Rynkevych, N. S. (2019), Methodical approach to evaluation the level of development of organizational culture of enterprises. Black Sea Economic Studies, vol. 48-2, pp. 112-118. https://doi.org/10.32843/bses.48-51.

63. Trushkina, N. V. and Rynkevych, N. S. (2019), Customer focus: basic definition approaches. Business Inform, no. 8, pp. 244-252. https://doi.org/10.32983/2222-4459-2019-8-244-252.

64. Trushkina, N. V. and Rynkevych, N. S. (2019), The digital transformation of corporate organizational culture: features, barriers and drivers in Suchasni protsesy transformatsii $u$ biznesi ta vyrobnytstvi: teoriia, metodolohiia, praktyka (zovnishnoekonomichna diialnist, promyslove vyrobnytstvo ta transport) [Modern processes of transformation in business and production: theory, methodology, practice (foreign economic activity, industrial production and transport)], Porohy, Dnipro, Ukraine.

How to cite this article? Як цитувати цю статтю?

Стиль - ДСТУ:

Трушкина Н. Рынкевич Н. Модернизация организационной культуры предприятий в эпоху цифровых преобразований. Agricultural and Resource Economics. 2020. Vol. 6. No. 2. Pp. 144-173. URL: http://are-journal.com.

Style - Harvard:

Trushkina, N. and Rynkevich, N. (2020), Modernization of organizational culture of enterprises in the epoch of digital transformations. Agricultural and Resource Economics, vol. 6, no. 2, pp. 144-173. URL: http://are-journal.com. 